\title{
Comparison of Rapid Anti-HCV Multi-sure Kit with Gold Standard ELISA
}

\author{
Rabia Irshad, Waquaruddin Ahmed and Syed Ejaz Alam \\ Pakistan Health Research Council (PHRC), Research Centre, Government of Pakistan, \\ Jinnah Postgraduate Medical Centre (JPMC), Karachi, Pakistan
}

\begin{abstract}
Objective: To compare the diagnostic yield of Multi-sure rapid HCV (hepatitis $\mathrm{C}$ virus) kit with ELISA.

Study Design: Comparative study.

Place and Duration of Study: Pakistan Health Research Council, specialised research center for gastroenterology and hepatology, from August 2016 to January 2017.

Methodology: A modified rapid anti-HCV kit was compared with ELISA. This rapid kit is multi-parameter qualitative immune chromatographic kit for the in-vitro detection of antibodies to HCV in human blood. Patients who came to PHRC, were tested using anti-HCV ELISA, and their test was run simultaneously on multi-sure HCV rapid kit were included in the study. Each positive and negative sample was included in this study. SPSS software was adapted for data analysis.

Results: A total of 420 samples were collected. Among them, 255 (61\%) were of male and 165 (39\%) were of female patients. Mean age was $35 \pm 14.33$ years. All the samples run for anti-HCV on ELISA were also run on multi-sure rapid kit. It is evident that $22.4 \%$ were reactive on ELISA and $23.6 \%$ were reactive on rapid kit, while $75.5 \%$ were non-reactive on ELISA and $68.1 \%$ were non-reactive on rapid kit. Borderline positive results were seen in $2.1 \%$ on ELISA and $5.0 \%$ on rapid kit. Sensitivity of rapid kit was $87.2 \%$, specificity $89.3 \%$ with $82.8 \%$ positive predictive value and $98.9 \%$ negative predictive value.

Conclusion: Multi-sure kit showed significantly, less non-reactive and more borderline results as compared to ELISA. Comparison of multi-sure rapid kit with ELISA showed that core antibody can be used as an alternate marker for ELISA. Other non-structural proteins including NS3, NS4 and NS5 were found to be less significant. So, it is concluded that this rapid kit may not be recommended as an alternative of ELISA, except for places where ELISA is not available.
\end{abstract}

Key Words: Hepatitis C-virus, Rapid kit, Sensitivity, Specificity, Structural proteins, Anti-HCV antibodies.

How to cite this article: Irshad R, Ahmed W, Alam SE. Comparison of rapid anti-HCV multi-sure kit with gold standard ELISA. J Coll Physicians Surg Pak 2019; 29(11):1053-6.

\section{INTRODUCTION}

Hepatitis $C$ virus is a RNA virus which has four structural and six non-structural proteins including NS2, NS3, NS4A, NS4B, NS5A and NS5B. ${ }^{1}$ An estimated $3 \%$ of world population is infected with hepatitis $C$ virus. ${ }^{2}$ In Pakistan, a national survey showed an overall $\mathrm{HCV}$ prevalence of $5 \% .^{3}$ According to $\mathrm{WHO}$ classification, Pakistan falls in the intermediate zone of infection for HCV. ${ }^{4}$ As no vaccine is available for hepatitis $\mathrm{C}$, it is necessary to diagnose and treat the infected person after appropriate screening. ${ }^{5}$ Numerous immunoassays have been developed for detecting HCV infection and most of these assays are principally based on the detection of antibodies against recombinant $\mathrm{HCV}$ polypeptide. 6 These assays include rapid ICT, ELISA

Correspondence to: Dr. Waquaruddin Ahmed, Pakistan Health Research Council (PHRC), Jinnah Postgraduate Medical

Centre (JPMC), Karachi, Pakistan

E-mail:waquaruddinahmed@gmail.com

Received: April 16, 2019; Revised: September 04, 2019;

Accepted: September 04, 2019 and EIA. Anti-HCV is typically identified by ELISA method, which is good screening assay ${ }^{7}$, and proved to be more sensitive. ${ }^{8}$ Four generations of ELISA have been developed, which detect different structural and non-structural proteins. Fourth generation simultaneously detects HCV capsid antigen as well as antibodies to the Core, NS3, NS4 and NS5 region of the virus. ${ }^{9}$ Rapid diagnostic ICT kits are less sensitive as compared to ELISA. ${ }^{10}$ Within rapid tests, some are sensitive while others are less sensitive. A recent study reported that the highest antibody response is observed against core HCV protein (85\%) followed by NS4 (54\%), NS5 (50\%) and NS3 (41\%); 11 whereas, antibodies against HCV non-structural proteins (NS3, NS4 and NS5) weakens consecutively. ${ }^{12}$

A new rapid kit by the name of MP diagnostic multi-sure anti-HCV kit has recently been introduced in Pakistan. It has four bands, one for the core and three for nonstructural proteins (NS3, NS4 and NS5). All these bands appear separately on the device. According to kit's literature, this kit has $99.28 \%$ sensitivity and $97.96 \%$ specificity with $99.25 \%$ diagnostic accuracy. The present 
Table I: Comparison of multi-sure rapid kit and ELISA

\begin{tabular}{|c|c|c|c|c|c|c|}
\hline & Multi-sure $(n=420)$ & ELISA $(n=420)$ & Multisure & Reactive & $\begin{array}{c}\text { ELISA } \\
\text { Non-reactive }\end{array}$ & Borderline \\
\hline Reactive & $99(23.6 \%)$ & $94(22.4 \%)$ & 99 & $82(87.2 \%)$ & $11(3.5 \%)$ & $6(66.7 \%)$ \\
\hline Non-reactive & $286(68.1 \%)^{*}$ & $317(75.5 \%)$ & 286 & $1(1.1 \%)$ & $283(89.3 \%)$ & $2(22.2 \%)$ \\
\hline Borderline & $21(5.0 \%)^{*}$ & $9(2.1 \%)$ & 21 & $2(2.1 \%)$ & $18(5.6 \%)$ & $1(11.1 \%)$ \\
\hline Invalid & $14(3.3 \%)$ & - & 14 & $9(9.6 \%)$ & $5(1.6 \%)$ & - \\
\hline Total & $420(100 \%)$ & $420(100 \%)$ & 420 & 94 & 317 & 9 \\
\hline
\end{tabular}

${ }^{*}$ Statistically significant $p<0.05$, Border Line results appear as grey zone.

Multi-sure were significantly less non-reactive 286 (68.1\%) and more borderline 21 (5.0\%) as compared to ELISA 317 (75.5\%), $9(2.1 \%)$ (p<0.05).

Table II: Comparison of core, NS3, NS4 and NS5 with ELISA.

\begin{tabular}{c|c|c|c|c}
\hline \multirow{2}{*}{ Multi-sure } & \multicolumn{3}{|c|}{ ELISA } & \multirow{2}{*}{ Total } \\
\cline { 2 - 4 } & Reactive & Non-reactive & Borderline & \\
\hline Core & & & & \\
0 & $82(87.2 \%)$ & $7(7.4 \%)$ & $5(5.3 \%)$ & 94 \\
NS3 & $12(3.7 \%)$ & $310(95.1 \%)$ & $4(1.2 \%)$ & 326 \\
\hline $1-3$ & $39(78.0 \%)$ & $7(14.0 \%)$ & $4(8.0 \%)$ & 50 \\
0 & $55(14.9 \%)$ & $310(83.8 \%)$ & $5(1.4 \%)$ & 370 \\
\hline NS4 & & & & 67 \\
$1-3$ & $48(71.6 \%)$ & $14(20.9 \%)$ & $5(7.5 \%)$ & 353 \\
0 & $46(13.0 \%)$ & $303(85.8 \%)$ & $4(1.1 \%)$ & \\
\hline NS5 & & & & 32 \\
$0.5-2.5$ & $22(68.8 \%)$ & $10(31.2 \%)$ & - & 388 \\
0 & $72(18.6 \%)$ & $307(79.1 \%)$ & $9(2.3 \%)$ & 420 \\
\hline Total & 94 & 317 & 9 & 370 \\
\hline
\end{tabular}

${ }^{*} 0.5,1,1.5,2,2.5$ and 3 are the values provided on reference identity

study was done to compare the diagnostic accuracy of MP diagnostic multi-sure anti-HCV rapid kit with ELISA. This study may define the sensitivity of multi-sure rapid kit.

\section{METHODOLOGY}

The study was conducted from August 2016 to January 2017 at Pakistan Health Research Council (PHRC). The study was comparative and inducted 420 blood samples as research object via convenient sampling technique using 95\% confidence level and absolute precision $2 \%$ and prevalence of disease ${ }^{13}$ as $5 \%$, in general population. Inclusion criteria were patients who come to PHRC, JPMC, specialised center for gastroenterology and hepatology, for screening of anti-HCV were included. An informed consent was taken from study participants and the study was done after approval of ethical committee of the institute.

In this study, a modified rapid kit of anti-HCV (multi-sureMP/Diagnostic) was compared with gold standard ELISA (4th generation - Murex) for sensitivity and specificity. This rapid kit is multi-parameter qualitative immune chromatographic kit for the in-vitro detection of antibodies to HCV in human blood. Five $\mathrm{ml}$ blood samples of patients coming for the screening of hepatitis $C$ were collected and serum was separated and tested for antiHCV using ELISA and multi-sure rapid kit, simultaneously. According to kit literature, 25 microliter serum was poured in well A of kit, sample was allowed to flow on the membrane, until it reached the blue line then three drops

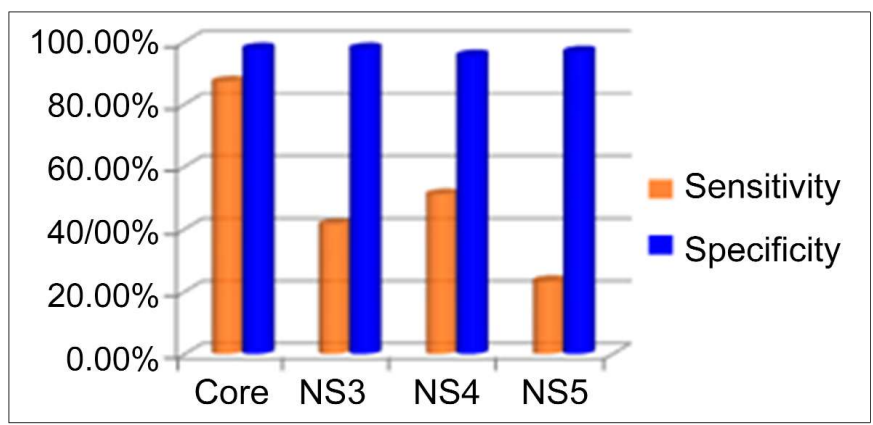

Figure 1: Graphical representation of sensitivity and specificity of core, NS3, NS4 and NS5.

$X$-axis: Structural and non-structural proteins.

Y-axis: Percentage of sensitivity and specificity.

of chase buffer (provided with kit) was added to the well B. Tab was pulled to allow the sample and buffer to mix and flow for 15 minutes. Control lines and test lines (bands) was observed and read with the help of reference identity scale (RIS) provided in the kit. Results were compared for sensitivity and specificity.

SPSS software was adapted for data analysis. The sensitivity and specificity of antibodies against each core, NS3, NS4 and NS5, were also analysed separately in comparison to ELISA.

\section{RESULTS}

A total of 420 samples were collected. Among them, 255 $(61 \%)$ were of males and $165(39 \%)$ were of females. Mean age of participants was $35 \pm 14.33$ years. Overall comparison of ELISA and rapid kit is shown in Table I. Multi-sure kit showed 99 (23.6\%) reactive samples and ELISA showed $94(22.4 \%)$. Sensitivity of the rapid kit had $87.2 \%$ (82 out of 94 ), and specificity $89.3 \%$ (283 out of 317 ) with $82.8 \%$ positive predictive value (82 out of 99) and $98.9 \%$ negative predictive value (283 out of 286 ). Fourteen samples on rapid kit showed invalid results, i.e. no color band appeared on the control line. Twenty-one samples were borderline on multi-sure kit, i.e. single NS4 or NS5 test line visible with intensity $\geq 1.0$, according to reference scale of kit. Multi-sure were significantly less non reactive $286(68.1 \%)$ and more borderline 21 (5.0\%) as compared to ELISA 317 (75.5\%), 9 (2.1\%) $(p<0.05)$.

Table II shows that out of 94 ELISA reactive, 82 (87.2\%) were core antibody reactive. The positivity of NS3 was $78 \%$, NS4 was $71.6 \%$, and NS5 was $68.8 \%$. 
Comparison of the sensitivity and specificity of antibodies against core, NS3, NS4 and NS5 with ELISA is shown via graph in Figure 1. It showed that $87.2 \%$ of core positive cases were ELISA positive and $95.1 \%$ core negative were ELISA negative.

\section{DISCUSSION}

This study showed that overall multi-sure rapid kit had lower sensitivity $(87.2 \%)$ and specificity $(89.3 \%)$, which is much lower than the sensitivity $(99.28 \%)$ and specificity $(97.96 \%)$ claimed by the manufacturer. Another study conducted in the same research centre (PHRC) compared the sensitivity and specificity of three rapid kits with ELISA. ${ }^{10}$ That study reported 93\% sensitivity of ACON USA and $89 \%$ for membrane Canada, while Novis Germany had $86 \%$ sensitivity. If we compare present results of rapid MP diagnostic multisure rapid kit with the rapid tests reported in the earlier study, the results showed that rapid MP diagnostic multisure kit is less sensitive as compare to most of the other rapid tests.

Multi-sure rapid kit, according to its literature, can detect structural proteins core and non-structural proteins NS3, NS4 and NS5 of the virus, but few studies have shown that antibody responses against $\mathrm{HCV}$ non-structural protein (NS3, NS4 and NS5) were erratic ${ }^{14}$ and NS3 and core antibody seems to be predominant. ${ }^{15}$ Therefore, core antibody may be significant to interpret.

In the present study, core antibody positivity was $87.2 \%$ for those who were reactive to ELISA, while core antibody negativity was $95.1 \%$ which was also negative on ELISA. This suggests that core antibody results are closer to the results of ELISA. Other non-structural proteins including NS3, NS4 and NS5 were found to be less significant as described in Table II. International research also proved that core antibody was more immune reactive protein reacting with $78.8 \%$ and $99.3 \%$ of acute and chronic samples, respectively 16 ; and core antigen based testing has a sensitivity ranging from 80 to $99 \%$ and specificity ranging from $96 \%$ to $100 \% .17$

In another comparative study of multi-sure kit and ELISA, the authors also hesitate to declare this kit as reliable in high incidence areas, and poor migration of serum was also reported on the flow device. ${ }^{5}$ Furthermore, its interpretation is more complex as intensity of the various lines is used and there is inter observer variation. However, research should be continued in search of cost-effective and more precise and simpler methods of detection for HCV, which can be performed at remote areas for screening purposes where basic necessities of life is not available.

\section{CONCLUSION}

Rapid kit named multi-sure kit showed significantly less non-reactive and more borderline results as compared to ELISA. Comparison of multi-sure rapid kit with ELISA showed that core antibody can be used as an alternate marker for ELISA. Other non-structural proteins including NS3, NS4 and NS5 were found to be less significant. So, it is concluded that this rapid kit may not be recommended as an alternative of ELISA, except for places where ELISA is not available.

\section{FUNDING:}

This study was funded by Pakistan Health Research Council.

\section{ETHICAL APPROVAL:}

Study was done after approval of Ethical Review Committee of Pakistan Health Research Council.

\section{PATIENTS' CONSENT:}

Informed consents were taken from study participants.

\section{CONFLICT OF INTEREST:}

Multi-sure rapid kits were provided by the manufacturer (MP-Diagnostics).

\section{AUTHORS' CONTRIBUTION:}

$\mathrm{RI}$ : Research idea, data collection, laboratory/bench work, manuscript writing.

WA: Supervision, manuscript review.

SEA: Data analysis, sample size calculation.

\section{REFERENCES}

1. Sillanpää $M$, Melén $K$, Porkka $P$, Fagerlund $R$, Nevalainen $K$, Lappalainen $\mathrm{M}$, et al. Hepatitis $\mathrm{C}$ virus core, NS3, NS4B and NS5A are the major immunogenic proteins in humoral immunity in chronic HCV infection. Virol $J$ 2009; 6:84.

2. Gupta E, Bajpai M, Choudhary A. Hepatitis C virus: Screening, diagnosis and interpretation of laboratory assays. Asian $J$ Transfus Sci 2014; 8:19-25.

3. Qureshi H, Bile KM, Jooma R, Alam SE, Afridi HU. Prevalence of hepatitis $B$ and $C$ viral infections in Pakistan: Finding of a national survey appealing for effective prevention and control measures. East Mediterr Health J 2010; 16 Suppl:S15-23.

4. Khan RAW, Ahmed W, Alam SE, Arif A. Screening of HBsAg and anti-HCV from tertiary care, private and public sector hospitals. Pak J Med Res 2011; 50:20-3.

5. Kosack CS, Nick S. Evaluation of two rapid screening assays for detecting hepatitis $C$ antibodies in resource-constrained settings. Trop Med Int Health 2016; 21:603-9.

6. Kesli R, Ozdemir M, Kurtoglu MG, Baykan M, Baysal B. Evaluation and comparison of three different anti-hepatitis $C$ virus antibody tests based on chemiluminescence and ELISA method used in the diagnosis of hepatitis $C$ infection in Turkey. $J$ Int Med Res 2009; 37:1420-9.

7. Maity S, Nandi S, Biswas S, Sadhukhan SK, Saha MK. Performance and diagnostic usefulness of commercially available ELISA and rapid kits for detection of HIV, HBV and HCV in India. Virol J 2012; 9:290.

8. Hussain N, Aslam M, Farooq R. Sensitivity comparison between rapid immune-chromatographic device test and ELISA in 
detection and sero-prevalence of HBsAg and anti-HCV antibodies in apparently healthy blood donors of Lahore, Pakistan. Int J Med 2011; 5:685-7.

9. Kamili S, Drobeniuc J, Araujo AC, Hayden TM. Lab diagnostics for hepatitis C virus infection. Clin Infect Dis 2012; 55(Suppl 1): S43-8.

10. Hayder I, Ahmed W, Alam SE. Comparison of different ICT kits for HBsAg and anti-HCV using gold standard ELISA. Pak $J$ Med Res 2012; 51:72-6.

11. Kheirabad AK, Farshidfar G, Gouklani H. Cross-reactivity values in hepatitis $C$ infection and a solution to detect true positive serums by third generation of ELISA Test. Int J Med Res Health Sci 2016; 5:81-89.

12. Toyoda H, Kumada T, Kiriyama S, Sone $Y$, Tanikawa $M$, Hisanaga $\mathrm{Y}$, et al. Changes in hepatitis $\mathrm{C}$ virus (HCV) antibody status in patients with chronic hepatitis $\mathrm{C}$ after eradication of HCV infection by interferon therapy. Clin Infect Dis 2005; 40: e49-54.

13. Arif A, Ahmed W, Alam SE, Qureshi H. Active disease in chronic hepatitis C patients with normal alanine amino-transferase. J Coll Physicians Surg Pak 2012; 22:488-91.

14. Beld $M$, Penning $M$, van Putten $M$, Lukashov $V$, van $\operatorname{den}$ Hoek $A$, McMorrow $\mathrm{M}$, et al. Quantitative antibody responses to structural (Core) and nonstructural (NS3, NS4, and NS5) hepatitis $\mathrm{C}$ virus proteins among seroconverting injecting drug users: Impact of epitope variation and relationship to detection of HCV RNA in blood. Hepatology 1999; 29:1288-98.

15. Ishii K, Ishibashi M, Ohtake T, Kano S, Saito H, Watanabe K. Characterization of antibodies against core, NS3, NS4 and NS5 region of hepatitis $C$ virus in patients with hepatitis C. Rinsho Byori 1997; 45:1156-62.

16. Araujo AC, Astrakhantseva IV, Fields HA, Kamili S. Distinguishing acute from chronic hepatitis $\mathrm{C}$ virus (HCV) infection based on antibody reactivities to specific HCV structural and non-structural proteins. J Clin Microbiol 2011; 49: 54-7.

17. Firdaus R, Saha K, Biswas A, Sadhukhan PC. Current molecular methods for the detection of hepatitis $C$ virus in high risk group population: A systematic review. World J Virol 2015; 4:25-32. 